\title{
Active University Teaching and Engaged Student Learning: A Mixed Methods Approach
}

\author{
Celeste A. Wheat \\ University of West Alabama \\ Yan Sun \\ Mississippi State University \\ Jessica C. Wedgworth \\ University Charter School \\ Martha M. Hocutt \\ University of West Alabama
}

\begin{abstract}
The purpose of this research was to examine how learning space design and implementation of an active learning pedagogy based on the $5 E$ Instructional Model influence university faculty's teaching practices and students' engagement. Faculty Fellows were recruited from a public, medium-sized university in the United States to teach courses, typically taught in a traditional classroom setting, in a new Active Learning Center (ALC) classroom. The classroom was funded by a Steelcase ${ }^{\circledR}$ Education Active Learning Center Grant that provided innovative and dynamic classroom furnishings and technology that allowed mobility and flexibility for both instructors and students. Quantitative and qualitative data were collected concurrently in this study. The quantitative analysis results indicated that the ALC learning experience significantly improved students' class participation and cognitive attentiveness, but had no effect on improving their meaningful processing of new information. The qualitative analysis results, while providing new insights into the quantitative findings, revealed the faculty fellows' changes and weaknesses in teaching practices and the mechanism of the ALC in supporting active learning. Implications of these findings and directions for future research are discussed.
\end{abstract}

Keywords: 5E Instructional Model, active learning, higher education, student engagement.

\section{Introduction}

Higher education scholars have argued that teaching pedagogies in higher education, which continue to use the traditional instructor-centered lecture model within static and inflexible classroom settings, presents a mismatch in preparing college students for a $21^{\text {st }}$-century, technology based society (Park \& Choi, 2014). Although there is an abundance of scholarly literature related to the application of active learning pedagogies within $\mathrm{K} / 12$ educational settings (Keengwe, 2015; Sullivan, 2015; Basye, Grant, Hausman, \& Johnston, 2015), there is a dearth of empirical literature that focuses on the integration of active learning pedagogy and classroom space design in higher education (Brooks, 2011; 2012; Brooks, Walker, \& Baepler, 2014; Jessop, 
Gubby, \& Smith, 2012; Park \& Choi, 2014). This study adds to the small, but growing, research base regarding the impact of classroom design and pedagogy on student engagement, motivation, and learning and faculty teaching practices in a university setting.

\section{Purpose}

This research explored the effect of the Active Learning Center (ALC) (see Figure 1) experience on student engagement and the impact of the ALC teaching experience on Faculty Fellows' teaching practices. Specifically, the impact of the 5E pedagogy and an active learning environment on students and faculty is examined. Research questions addressed are: (a) Does learning experience in the ALC improve students' learning engagement? (b) How does ALC experience make learning more engaging? and (c) How does ALC teaching experience change instructors' teaching practices?

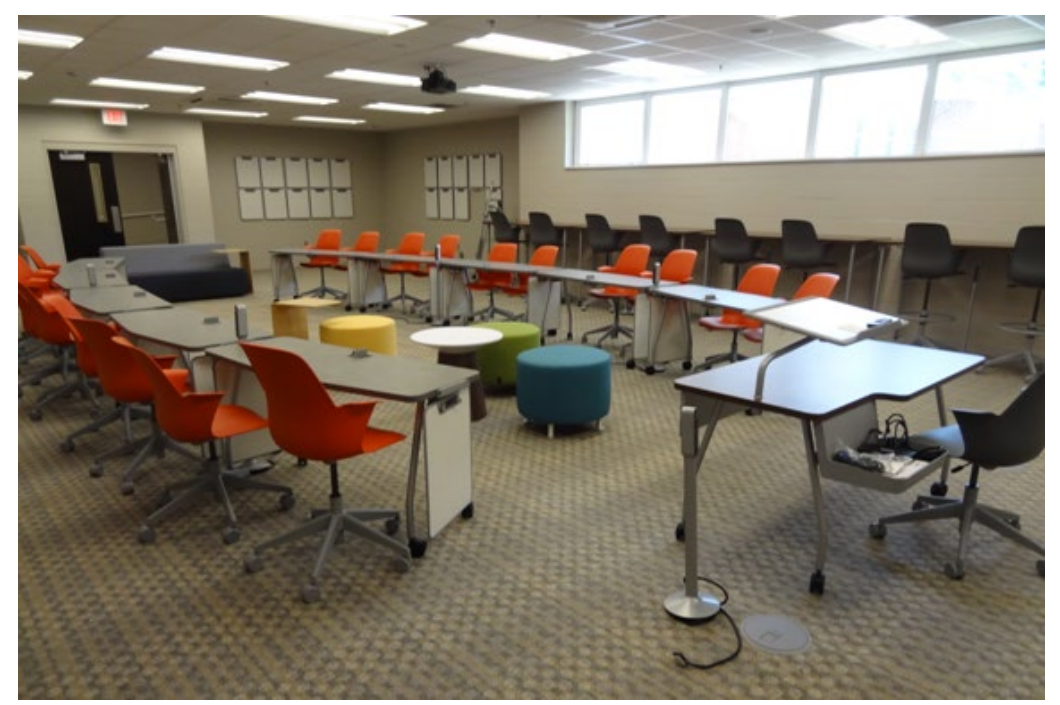

Figure 1. Active learning center

\section{Context of the Study}

The researchers conducted this study at a mid-sized regional university located in a rural and underdeveloped region of the southeastern United States characterized by high levels of poverty, poor test scores in K/12 schools, low levels of educational achievement, high percentages of high school dropouts, low standards of living, high unemployment rates, and low levels of funding for $\mathrm{K} / 12$ schools. The typical student is a first-generation, low-income minority that is not prepared for college-level work. As a result, 22-24\% of students succumb to academic suspension. Therefore, the University is in a unique position to offer opportunities to a large number of underrepresented and unprepared students.

Steelcase ${ }^{\circledR}$ began designing office furnishings in 1914 and is actively involved in supporting community initiatives. Steelcase ${ }^{\circledR}$ organizational structure includes an Education Division that seeks to better understand how learning occurs and to design furnishings for an optimal learning environment (Steelcase ${ }^{\circledR}, 2016$ ). In 2015, Steelcase ${ }^{\circledR}$ solicited proposals for Active Learning Center (ALC) grants from K/12 schools and institutions of higher education for the purpose of studying how Steelcase ${ }^{\circledR}$ furnishings affect teaching and learning. Out of over 450 
proposals submitted to Steelcase ${ }^{\circledR}, 11$ institutions received an ALC award, including the university discussed in this study. In the summer of 2015, the university established the ALC equipped with Steelcase ${ }^{\circledR}$ furnishings and technology and prepared to implement the study. To that end, the researchers chose faculty from across campus to teach in the ALC through an application process which required submission of a teaching philosophy and Curriculum Vitae and designated the faculty participants Faculty Fellows.

Prior to the beginning of the Fall 2015 term, 13 Faculty Fellows participated in an ALC orientation that modeled the 5E Instructional Model and demonstrated multiple modes of classroom configurations (see Figures 2, 3, \& 4) and technologies (i.e., mobile charging stations, ENO Interactive White Board, and iPads). Faculty Fellows were also exposed to a variety of technology tools for teaching (e.g., Kahoot, Padlet, Classtools.net, Blabberize). The researchers repeated the process at the beginning of the spring 2016 term with 11 Faculty Fellows.

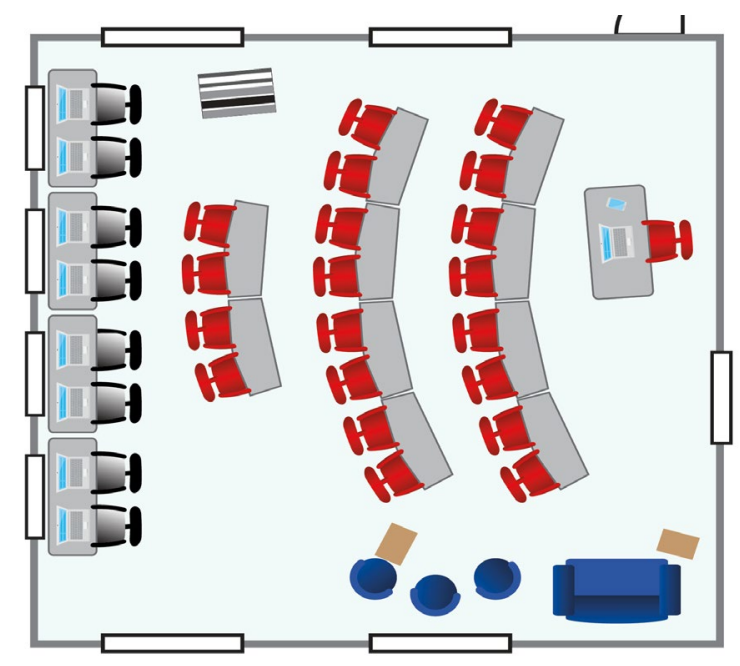

Figure 2. Lecture Mode

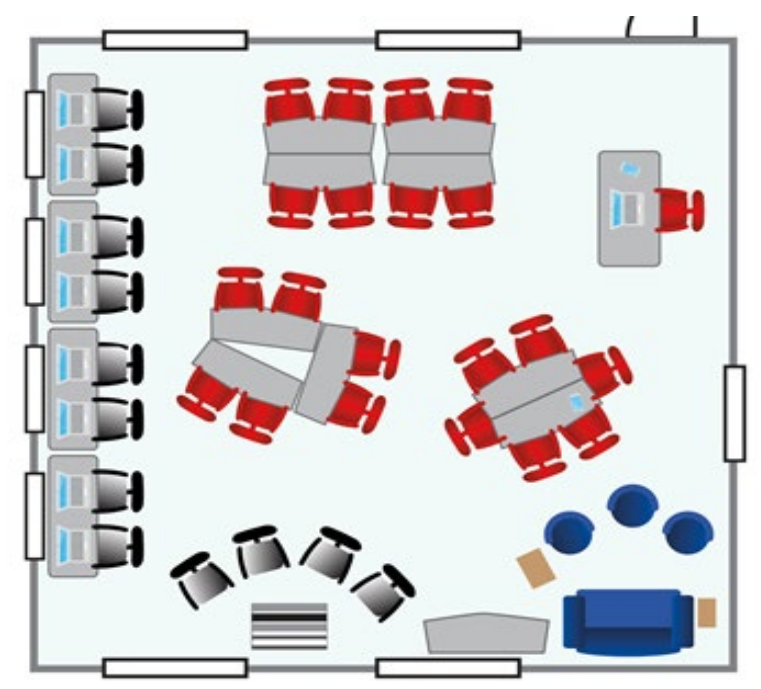

Figure 3. Group Work Mode 


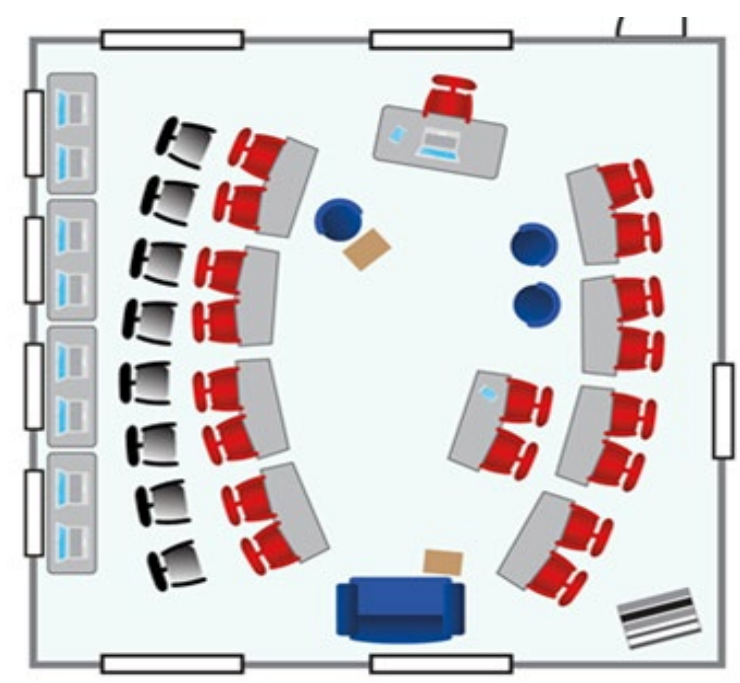

Figure 4. Discussion Mode

\section{Conceptual Framework}

The 5E (Engage, Explore, Explain, Elaborate, and Evaluate) Instructional Model developed by Rodger W. Bybee and colleagues was specified by the researchers of this study in their Steelcase Active Learning Center grant proposal as the pedagogy supporting active learning in ALC. This study, therefore, investigated the effects of ALC experience on learning engagement and teaching practices through the lens of the 5E Model. The student-centered 5E Instructional Model is grounded in a constructivist perspective associated with active learning and shown in empirical studies to significantly increase student engagement and instructional effectiveness (Bybee, 2014; Kolis, Krusack, Stombaugh, Stow, \& Brenner, 2011; Tanner, 2010). Constructivism is one of the key theoretical paradigms that underlies many active learning pedagogical models. Constructivism places students at the center of the learning process while instructors assume the role of facilitating students' interaction with content and knowledge creation (Lumpkin, Achen, \& Dodd, 2015). The 5E Instructional Model incorporates "decades of research into a brief and memorable [and user-friendly] set of five words," (Tanner, 2010, p. 160) and provides a sequencing of classroom events that allows for optimal student learning and engagement. Instructors using this model use the following sequence or order in planning their classes:

1. In the engage stage, instructors begin a class by seeking to engage students' interest in a topic through demonstrations, use of technology tools, class activity, etc., which allows the instructor to assess students' prior knowledge.

2. In the explore phase, instructors facilitate students in a process of exploring previous knowledge collaboratively through communication with classmates, questioning and critical thinking.

3. In the explain stage, instructors explain topics, introduce new vocabulary, and clarify misconceptions. This stage may closely resemble a traditional lecture format.

4. In the elaboration stage, instructors encourage students to apply new concepts to new and different contexts.

5. In the evaluate stage, instructors evaluate student learning, which may take on multiple forms such as writing a 1-minute paper or taking a quiz (Bybee, 2014). 
Although this model may be widely adapted for learners of all ages and instruction of any discipline, Bybee (2014) recommends that instructors should avoid omitting a stage or making changes to the order of the stages, as this has been shown to reduce the effectiveness of the model in relation to student learning and motivation.

\section{Literature Review}

This literature review examines scholarship related to the influence of active learning, faculty pedagogy, and learning space design on student learning and engagement. The key themes that have emerged from this literature review address issues pertaining to: 1) barriers and facilitators of active learning, 2) faculty professional development, and 3) classroom learning space.

\section{Barriers and Facilitators of Active Learning}

The traditional lecture continues to represent a popular method of course content delivery within the classrooms of American colleges and universities (Beichner 2014; Folkins, Friberg, \& Cesarini, 2015; Miller \& Metz 2014). With this mode of content delivery, students passively learn through memorizing vast amounts of information in an instructor-focused classroom environment where the lecture method is used. Research indicates that the lecture format is not the most effective way to teach students who possess differing learning styles or prepare students with the necessary competencies for $21^{\text {st }}$ century jobs (Folkins, Friberg \& Cesarini, 2015; Lumpkin, Achen, \& Dodd, 2015; Miller \& Metz, 2014; Park \& Choi, 2014). In fact, instructors that only rely on a lecture to deliver course content may constrain student learning (Beichner 2014; Lumpkin, Achen, \& Dodd, 2015).

In order to overcome the learning barriers engendered by passive, instructor-focused teaching methods, higher education stakeholders have called for a "paradigm shift" from instructor-centered to student-centered pedagogical models capable of helping students transition from passive to active learning (Harris \& Cullen, 2008; Umbach \& Wawrzynski, 2005). Numerous higher education scholars (Braxton, Milem, \& Sullivan, 2000; Brooks, 2011; 2012; Brooks \& Solheim, 2014; Brooks, Walker, \& Baepler, 2014; Folkins, Friberg \&, Cesarini, 2015; Lumpkin, Achen, \& Dodd, 2015; Umbach \&Wawrzynski, 2005) document the benefits of active learning strategies in improving student learning outcomes and engagement. As Harris and Cullen (2008) contextualize, "efforts to . . . [shift] more to a learner-centered [model in higher education] have been driven by a new understanding about how humans learn [by] draw[ing] from neuroscience, biology, and cognitive psychology." Furthermore, the authors contend that we "know more than ever before about how people learn, what inhibits learning, and how people learn differently." (p. 22)

Improvements in student learning outcomes and engagement, in turn, have been consistently linked to increases in student recruitment and retention (Braxton, Milem, \& Sullivan, 2000). Studies (Braxton, Milem, \& Sullivan, 2000; Chickering \& Gamson, 1987; Miller \& Metz, 2014; Umbach \& Wawrzynski, 2005) have documented that faculty-to-student and student-to-student interactions involving active learning are among the most significant contributors to college student achievement and retention.

Active learning. Since the 1990s, active learning has been a popular buzz word in higher education. Active learning transforms students from passive learners to "engaged participants in the classroom through the use of in-class written exercises, games, problem sets, audience- 
response systems, debates, discussion, etc." (Miller \& Metz, 2014, p. 246). It also transforms the instructor's role from a "'sage on the stage' to a 'guide on the side" (Miller \& Metz, 2014, p. 246). Consequently, students are able to become more self-directed, independent learners (Miller $\&$ Metz, 2014). In contrast to the lecture method which encourages rote memorization, "active learning encourages students to accomplish higher-order objectives on Bloom's taxonomy, such as analysis, synthesis, and evaluation" (Miller \& Metz, 2014, p. 246).

Research also suggests that active learning, compared to the lecture format, is more effective in promoting enhanced thinking and writing skills (Lumpkin, Achen, \& Dodd, 2015). Miller and Metz (2014) explain that active learning strategies enhance student learning in respect to "processing of information..., problem-solving abilities, and critical thinking skills" (p. 246). The learning outcomes associated with active learning strategies, such as building collaborative skills with peers or honing critical thinking skills, are better suited to prepare students for careers within a $21^{\text {st }}$ century "information and technology-based society [which] has come to regard memorizing facts and knowledge as no longer absolute" (Park \& Choi, 2014, p. 751). Active learning is more beneficial to students after the completion of a course in equipping them with the ability to apply their knowledge to real-world situations (Lumpkin, Achen, \& Dodd, 2015).

The 5E (engage, explore, explain, elaborate, evaluate) instructional model. Empirical research from multiple fields of study supports the idea that the order or sequencing of activities is critically important to factors of student success, such as motivation, retention of information, and understanding of complex material (Bybee, 2014; Kolis et al., 2011; Sickel, Witzig, Vanmail, \& Abell, 2013; Tanner, 2010). The flexibility of the 5E Instructional Model makes it applicable to learners of all ages and within any academic discipline and is associated with helping students view instructors as demonstrating the qualities (e.g., approachable, creative, interesting, enthusiastic) associated with excellence in teaching (Kolis, et al., 2011). Yet, despite evidence that supports the effectiveness of active learning strategies, the 5E Instructional Model and other active learning pedagogies have not been widely adopted among faculty teaching at American institutions of higher learning (Miller \& Metz, 2014).

\section{Faculty Professional Development}

Faculty behaviors. The extant literature suggests that faculty have a significant influence on student learning and engagement (Daly, 2011; Folkins, Friberg \& Cesarini, 2015; Harris \& Cullen, 2008; Umbach \& Wawrzynski, 2005; Williams, 2010). Chickering and Gamson's (1987) groundbreaking study, Principles of Good Practice for Undergraduate Education, points to seven core influences on student learning and engagement that further support the effectiveness of active learning pedagogies in relation to faculty: 1.) promoting faculty-to-student interaction, 2) encouraging cooperative student peer relationships, 3) employing active learning strategies, 4) providing timely feedback on student work, 5) stressing "time on task," 6) establishing "high expectations," and 7) valuing differing talents and learning styles (Chickering \& Gamson, 1987, p. 2). Although "certain factors of excellence in teaching are personality-based, others, including effective communication, realistic expectations, and 'creative' and 'interesting' ways of structuring the class, can be learned and improved through instructional design training" (Kolis et al., 2011, p. 35).

Lack of support for professional development in collegiate teaching. Faculty who receive extensive training in their respective fields, typically do not receive formal training in college teaching (Kolis et al., 2011). Harris and Cullen (2008) explain, "it is not uncommon for a new 
assistant professor to have never taught a class prior to being hired" (p. 22). Faculty also have to balance teaching with the service and research components of their role. Among the interdisciplinary sample of faculty who participated in the 5E Instructional Model training at the University of Wisconsin-Eau Claire, faculty reported basing their teaching style and philosophy on the form of content delivery they received as students (Kolis et al., 2011). Research indicates that gaining teaching "experience alone is not enough to improve teaching from the level where instructors naturally start" (Kolis et. al., 2011, p. 35). In considering the diverse array of responsibilities (e.g., service, research, advising, mentoring) that comprise a faculty role, Daly (2011) posits that "colleges and universities need to provide additional support for faculty development" (p. 4). For a true paradigm shift to occur, it must be the responsibility of the entire institution in terms of providing adequate financial support, training, technology, and support services (Daly, 2011; Harris \& Cullen, 2008).

Faculty learning communities. Faculty learning communities are cohorts of instructors (e.g., first-year faculty) who meet throughout an academic year to learn how to enhance teaching and student learning (Daly, 2011; Pavlechko \& Jacobi, 2014). These types of communities allow faculty to "experiment with new teaching practices in their classrooms or engage in self-designed teaching projects, while obtaining advice, feedback, and support from their faculty learning community colleagues" (Daly, 2011, p. 4). Emerging research points to the positive benefits of faculty learning communities, such as (a) adopting new pedagogical models, (b) enhancing scholarly productivity, (c) having more collegial relationships, and (d) observing improvement in students' critical thinking skills (Daly, 2011; Kolis et al., 2011; Pavlechko \& Jacobi, 2014). Pavlechko and Jacobi (2014) also maintain that effective professional development for faculty should be "faculty-driven," occur on a sustained basis, and involve the rethinking of active learning pedagogy in relationship to the key components of the learning environment that includes "students, instructor, technology, furnishings, and space" (p. 169). Although the positive outcomes of these communities are documented, very few empirical studies address the actual learning involved with faculty professional development.

\section{Classroom Learning Space}

Although still largely understudied, "there is a growing interest in the relationship between architectural design and pedagogy in higher education" (Brooks, 2011; 2012; Brooks \& Solheim, 2014; Brooks, Walker, \& Baepler, 2014; Jessop, Gubby, \& Smith, 2012, p.189). Scholars have begun to document the significant influence that learning space has on student learning, engagement, and instructor pedagogy (Brooks, 2011; 2012; Brooks \& Solheim, 2014; Folkins, Friberg \& Cesarini, 2015; Jessop, Gubby, \& Smith, 2012; Pavlechko \& Jacobi, 2014). Overall, research demonstrates a positive impact of these active learning spaces on student outcomes, as well as the importance of considering the physical learning space as a contributing factor to overall classroom success (Brooks, 2011; 2012; Brooks \& Solheim, 2014). As a result, higher education institutions are increasingly promoting flexible spaces that support learner-centered instruction. Pavlechko and Jacobi (2014) define learning space "as the physical location where teaching and learning take[s] place" (p. 169). Brooks, Walker, and Baepler (2014) clarify that a learning "space does not determine behavior, but influences how we act and relate within it in ways that may not be readily observable" (p. 2 [italics in original]).

Traditional learning spaces. Traditional learning spaces, such as lecture halls or auditoriums where seats face the front of the room, present a formidable barrier to the 
implementation of active learning pedagogies (Brooks, 2012; Jessop, Gubby, \& Smith, 2012; Pavlechko \& Jacobi, 2014; Peterson \& Gorman, 2014). Research indicates that traditional learning spaces are conducive to instructor-centered pedagogies (Brooks, 2012; Peterson \& Gorman, 2014). The fixed seating design of traditional learning spaces also limits faculty and student interactions (Brooks, 2012; Folkins, Friberg \& Cesarini, 2015; Jessop, Gubby \& Smith, 2012; Peterson \& Gorman, 2014).

Active learning spaces. In contrast, active learning classrooms provide flexible learning spaces that allow faculty to successfully adopt active learning strategies and increase opportunities for interaction with students (Brooks, 2011; 2012; Folkins, Friberg \& Cesarini, 2015; Jessop, Gubby, \& Smith, 2012, McArthur, 2015; Michael, 2007; Montgomery, 2008; Pavlechko \& Jacobi, 2014; Peterson \& Gorman, 2014). An active, "constructivist classroom" is a space that allows for "autonomy, initiative, active knowledge construction . . . [and] learnercommunities" (Montgomery, 2008, p. 126). The design of active learning spaces allows for students to engage in small group interactions as well as facilitates greater instructor-to-student interaction (Peterson \& Gorman, 2014).

In their multi-method study involving classroom observations, interviews with faculty, and student surveys, Jessop, Gubby, and Smith (2012) found that "teaching spaces influence how people teach, both in encouraging new forms of pedagogy and in constraining imagination about fresh possibilities" (p. 193). Additionally, in a quasi-experimental design study that compared instructor and student behavior in a traditional classroom versus a technologically-enhanced active learning classroom at a large university in the Midwest, Brooks (2012) found that different classroom spaces influenced faculty behavior and teaching practices. Specifically, traditional classroom spaces influenced faculty to use lecture content delivery and avoid active teaching strategies, while active learning pedagogies were more conducive to teaching in an active learning classroom space than lecture (Brooks, 2012).

Creating active learning spaces. As institutions of higher education consider creating active learning spaces, Folkins, Friberg, and Cesarini (2015) present nine design principles for creating active learning spaces which include;

- flexible seating conducive to group work;

- enough space for instructor movement and interaction with students;

- appropriate technology that facilitates group work and collaboration;

- good sight lines with a clear focal point;

- good acoustics for communications;

- easily accessible classroom entrances;

- adequate spaces for students to hangout near the classroom before and after class;

- simple zoned lighting; and

- enough windows to "add interest, character, and style to classroom spaces" (p. 59).

Among the design principles, access to technology and application of learning technology represent an important component of $21^{\text {st }}$-century learning environments (Folkins, Friberg, \& Cesarini, 2015; Pavlechko \& Jacobi, 2014). Further, in surveying 166 students at one university concerning their priorities for classrooms, Jessop, Gubby, and Smith (2012) reported that students' highest priorities included: tables for writing, "spacious rooms," comfortable seating and room temperature, and technology access (p. 196).

The influence of active learning space on student behaviors. A constructivist teaching philosophy in conjunction with an active learning space has been shown to improve student 
outcomes and increase instructor perceptions of student engagement (Sawers, Wicks, Mvududu, Seeley, \& Copeland, 2016). Using a quasi-experimental design to examine the effect of physical space on student learning by comparing student performance in active learning classrooms and traditional classrooms at the University of Minnesota, Brooks' (2011) research represents the first empirical study to document that "controlling for nearly all other factors, physical space alone can improve student learning even beyond students' abilities as measured by standardised test scores" (p. 725). In another study at The University of Minnesota, Brooks and Solheim (2014) surveyed 111 students in the fall of 2008 and 96 in the fall of 2009 to understand student perceptions of their learning in an active learning classroom. Additionally, for each semester they collected disaggregated grades for all students in the courses. The analysis of the data revealed that "instructors who modify their approach to teaching a course based on the physical environment in which it is conducted can improve significantly student learning across the board" (Brooks \& Solheim, 2014, pp. 59-60).

Several recent studies published in the Journal of Learning Spaces provide further empirical support that learning space can influence a students' behavioral, affective, and cognitive learning (Adedokun, Parker, Henke, \& Burgess, 2017; McArthur, 2015; Parsons, 2016; Rands \& Gansemer-Topf, 2017). Using an experimental design, McArthur (2015) studied a sample of 234 college students enrolled in 15 sections of a public speaking course and placed the students in three differing classroom spaces including: (a) traditional, b) versatile, and c) fluid. The results of this study demonstrated that the instructional environment influences student learning outcomes and that these influences are moderated by the instructor, which further demonstrates the importance of considering physical learning space as a facilitator of classroom success. A key finding of this study reveals, "instructors who are able to function within the fluid space can achieve higher learning results than they could in traditional classrooms" (McArthur, 2015, p. 14)

Allowing for a variety of active learning strategies in a flexible, open, student-centered space was used to demonstrate the impact of design on student engagement at Iowa State University, further highlighting the importance of assessment on classroom design (Rands \& Gansemer-Topf, 2017). Also in a university setting, analysis of an undergraduate liberal arts program determined that the program's active learning spaces empowered students to engage in dialogue, so much that they occasionally wished to disengage (Parsons, 2016). From a student perspective, it has been reported that flexible space enhanced their learning experience by supporting classroom engagement, demonstrating the importance of student perceptions when planning learning spaces (Adedokun, Parker, Henke, \& Burgess, 2017).

Moreover, research indicates that active learning spaces can foster educational alliances among students (Baepler \& Walker, 2014). Baepler and Walker studied the influence of active learning spaces on interpersonal relationships in the classroom at the University of Minnesota from 2008 to 2012. Using multiple forms of data collection including: a) student and faculty surveys," b) semi-structured interviews with faculty who taught in active learning centers, and focus groups, Baepler and Walker found that active learning spaces contributed to the formation of educational alliances in student-to-teacher relationships and student-to-student peer relationships (p. 29). Their study provides evidence that active learning spaces help students develop educational alliances with their peers that are based on: a) mutual respect, b) shared responsibility for learning, c) effective communication and feedback, d) cooperation, and e) trust and security (Baepler \& Walker, 2014). 
Evaluation of literature. The literature indicates that the transition from an instructorcentered to student-centered learning environment can be most effectively achieved through the adoption of an active learning pedagogy, implementation of faculty professional development programs, and the creation of a technology-infused active learning space. The literature also reveals a dearth of empirical data related to issues concerning: a) active learning spaces, b) student perceptions of active learning spaces, c) the relationship between classroom design and pedagogy, d) the effective implementation of faculty professional development communities, and e) integrating active learning spaces, pedagogy, and learning technologies (Brooks, 2011; 2012; Daly, 2011; Jessop, Gubby, \& Smith, 2012, Montgomery, 2008).

\section{Study Design}

The purpose of this study is bi-dimensional: (1) to investigate the effect of the ALC learning experience on student learning engagement, and (2) to examine the impact of the ALC teaching experience on Faculty Fellows' teaching practices. To serve this purpose, researchers adopted a two-phase explanatory sequential mixed methods research design (Creswell 2009). Phase 1 was a quantitative study collecting and analyzing pre and post ALC student survey data to answer the quantitative research question: Does the ALC learning experience improve student learning engagement? Phrase 2 was a qualitative study collecting and analyzing open-ended faculty fellow survey data and classroom observation data to answer two qualitative research questions: (1) How does the ALC make learning more engaging? (2) How does the ALC teaching experience change instructor teaching practices? The qualitative investigation sought to help interpret and understand the quantitative results in this study, and to furnish insights into learning experience and teaching practices in ALC classroom.

\section{Participants}

Study participants consisted of students who took courses in the ALC and Faculty Fellows who taught in the ALC in the 2015 Fall and 2016 Spring semesters. Specifically, there were 130 students (69 from 2015 Fall and 61 from 2016 Spring). Students were both graduate and undergraduate and from a diverse variety of majors and colleges, including the College of Education, College of Business, College of Liberal Arts, and College of Natural Sciences and Mathematics, as well as from the Division of Nursing. Table 1 provides information on the age of the student participants.

\section{Table 1. Age distribution}

\section{Age Group $\quad$ Number of Participants}

$18-22 \quad 107$

23-26 10

27-32 4

$33+\quad 9$

A total of 19 Faculty Fellows, including all faculty ranks (Assistant Professor, Associate Professor, and Professor) and all colleges plus the Division of Nursing, participated in this study. Additionally, one faculty participant was an instructor and one the Director of Counseling. 


\section{Instruments and Data Collection}

Researchers adapted the Engaged Learning Index (ELI) developed and validated by Schreiner and Louis (2006) to create the instrument used for collecting student survey data. The original instrument included 15 items and can be found in Appendix A. In the validation, Schreiner and Louis (2006) extracted through exploratory factor analysis three components that accounted for $54.19 \%$ of the variance and the three components are the three factors in the ELI: factor 1 of Meaningful Processing comprised of items 1-9 with a coefficient alpha estimate of .90 $(\alpha=.90)$, factor 2 of Participation comprised of items 10-12 with a coefficient alpha estimate of .74 $(\alpha$ $=.74$ ), and factor 3 of Focused Attention comprised of item 13-15 with a coefficient alpha estimate of .79 $(\alpha=.79)$. According to Schreiner and Louis (2006), the factor Meaningful Processing represents cognitive processing of new information and efforts to relate new material to pre-existing knowledge or determine its personal relevance, the factor Participation represents student learning through active involvement and contribution to classroom discussions, and the factor Focused Attention is associated with cognitive attentiveness during class.

The researchers used only 14 items from the ELI to collect pre-survey data from the students, leaving out item 4 because this item does not fit into the research situation of this study. In the post-survey, the researchers used the same items but rephrased them to fit the specific ALC situation. Appendix B contains the rephrased ELI used for the post-survey data collection. Both the pre- and post-survey items used a five-point Likert Scale (Strongly Disagree, Disagree, Neither Disagree or Agree, Agree, and Disagree). ALC students completed the pre-survey questionnaire at the beginning of the 2015 Fall and 2016 Spring semesters, and the post-survey questionnaire at the end of the two semesters. Cronbach's $\alpha$ was calculated for the three components (Meaningful Processing, Participation, and Focused Attention) from student survey data. The results are shown in Table 2.

\section{Table 2. Cronbach's $\alpha$ calculated from 2015 fall and 2016 spring data}

\begin{tabular}{|c|c|c|c|}
\hline \multicolumn{2}{|c|}{2015 Fall and 2016 Spring Pre-Survey Data } & \multicolumn{2}{|c|}{2015 Fall and 2016 Spring Post-Survey Data } \\
\hline Components & Cronbach's $\alpha$ & Components & Cronbach's $\alpha$ \\
\hline $\begin{array}{l}\text { Meaningful } \\
\text { Processing (Items 1- } \\
\text { 8) }\end{array}$ & .81 & $\begin{array}{l}\text { Meaningful Processing } \\
\text { (Items 1-8) }\end{array}$ & .94 \\
\hline $\begin{array}{l}\text { Participation } \\
\text { (Items 9-11) }\end{array}$ & .65 & $\begin{array}{l}\text { Participation } \\
\text { (Items 9-11) }\end{array}$ & .56 \\
\hline $\begin{array}{l}\text { Focused Attention } \\
\text { (Items12-14) }\end{array}$ & .86 & $\begin{array}{l}\text { Focused Attention } \\
\text { (Items12-14) }\end{array}$ & .91 \\
\hline
\end{tabular}

\section{Faculty Open-ended Surveys and Data Collection}

For the 2015 Fall semester and 2016 Spring semester, the researchers conducted professional development training for ALC Faculty Fellows prior to the beginning of the semesters. At the end of the training, Faculty Fellows took the pre-survey that included three open-ended questions: 1) How do you think teaching a class in the Steelcase ${ }^{\circledR}$ ALC will influence your students' learning experience? 2) How do you think the Steelcase ${ }^{\circledR}$ ALC will influence your students' 
motivation to learn and their engagement in the class? 3) How will using the 5E (Engage, Explore, Explain, Elaborate, and Evaluate) Instructional Model while teaching in the Steelcase ${ }^{\circledR}$ ALC influence your teaching practices? At the end of the two semesters, Faculty Fellows took the post-survey that included three similar open-ended questions: 1) How do you think teaching your class in the Steelcase ${ }^{\circledR}$ ALC influenced your students' learning experience? 2) How do you think the Steelcase ${ }^{\circledR}$ ALC influenced your students' engagement in your class? 3) How did using the 5E (Engage, Explore, Explain, Elaborate, and Evaluate) Instructional Model to teach in the Steelcase ${ }^{\circledR}$ ALC affect your teaching practices? The pre-survey was meant to determine the Faculty Fellows' anticipation of their ALC teaching experience, and the post-survey served to record the Faculty Fellows' reflections on their ALC teaching experience.

\section{Classroom Observation Protocol and Data Collection}

The researchers created the Classroom Observation Protocol to capture the active learning components as indicated by these seven elements;

- learning activities present to attract or motivate students;

- students actively involved in learning activities;

- instructor encourages students to think critically and/or creatively;

- instructor encourages students to express ideas freely;

- instructor gives students opportunity to perform exploration;

- instructor creates an atmosphere conducive to doing learning activities; and

- collaborative learning (group learning) takes place where each student actively contributes to the group.

One internal observer from the research team and two outside observers, trained by the internal observer in using the observation protocol and notating observations, made classroom observations. The purpose of using outside observers was to enhance the objectivity and reliability of the observations (O'Leary, 2014).

The observation team completed an inter-rater reliability check before independent observations through observing the same classroom and calculating the inter-rater reliability (71.4\%). Observation notes were also compared, disagreements discussed, and each observation element re-visited until an agreement was reached suggesting $100 \%$ reliability. After the interrater reliability check, the three observers completed independent observations. In both 2015 Fall and 2016 Spring semesters, each observer observed 3 Faculty Fellows resulting in data collected from observation of 18 Faculty Fellows. When conducting observations, the observers checked the presence of the seven elements and took extensive notes about any elements observed.

\section{Measures}

The student pre- and post-survey responses were scored: (1) Numeric numbers were assigned to each category in the five-point Likert Scale of the student survey data: $1=$ Strongly Disagree, 2 $=$ Disagree, $3=$ Neither Disagree or Agree, $4=$ Agree, and $5=$ Strongly Agree; and (2) The last four items (item 11-14) were negative items and reverse-scored. Each student had four scores:

- ELI score: the overall score for all 14 survey items

- Meaningful Processing score: the score for the Meaningful Processing component derived from items 1-8 
- Participation score: the score for the Participation component derived from items 9-11

- Focused Attention score: the score for the Focused Attention component derived from items $12-14$

\section{Student Survey Data Analysis}

Dependent samples t-tests and Wilcoxon signed rank tests were conducted in analyzing the student pre- and post-ELI survey data. Specifically, the 2015 Fall student survey data were analyzed with two dependent samples t-tests and two Wilcoxon signed rank tests, and the 2016 Spring survey data were analyzed with four dependent samples t-tests. Table 3 shows the details of the statistical tests performed on the student survey data. As shown by the Shapiro-Wilk test p-values reported in Table 2, researchers conducted two Wilcoxon signed rank tests instead of dependent samples t-tests because the corresponding data were not normally distributed.

Table 3. Dependent samples t-tests and Wilcoxon signed rank tests conducted

\begin{tabular}{|c|c|}
\hline 2015 Fall student survey data analysis & 2016 Spring student survey data analysis \\
\hline $\begin{array}{l}\text { Dependent samples t-test } \mathbf{1} \text { : } \\
\text { (Shapiro-Wilk test p-value is .379 ) } \\
\text { Comparing the overall } 2015 \text { Fall pre and post } \\
\text { ELI scores. }\end{array}$ & $\begin{array}{l}\text { Dependent samples t-test 3: } \\
\text { (Shapiro-Wilk test p-value is . 196) } \\
\text { Comparing the overall } 2016 \text { Spring pre and } \\
\text { post ELI scores. }\end{array}$ \\
\hline $\begin{array}{l}\text { Dependent samples t-test 2: } \\
\text { (Shapiro-Wilk test p-value is .445) } \\
\text { Comparing the pre and post Meaningful } \\
\text { Processing scores in the } 2015 \text { Fall student } \\
\text { survey data. }\end{array}$ & $\begin{array}{l}\text { Dependent samples t-test 4: } \\
\text { (Shapiro-Wilk test p-value is .243) } \\
\text { Comparing the pre and post Meaningful } \\
\text { Processing scores in the } 2016 \text { Spring student } \\
\text { survey data. }\end{array}$ \\
\hline $\begin{array}{l}\text { Wilcoxon signed rank test 1: } \\
\text { (Shapiro-Wilk test p-value is .005) } \\
\text { Comparing the pre and post Participation } \\
\text { scores in the } 2015 \text { Fall student survey data. }\end{array}$ & $\begin{array}{l}\text { Dependent samples t-test 5: } \\
\text { (Shapiro-Wilk test p-value is .130) } \\
\text { Comparing the pre and post Participation } \\
\text { scores in the } 2016 \text { Spring student survey data. }\end{array}$ \\
\hline $\begin{array}{l}\text { Wilcoxon signed rank test 2: } \\
\text { (Shapiro-Wilk test p-value is } \mathbf{. 0 0 1} \text { ) } \\
\text { Comparing the pre and post Focused } \\
\text { Attention scores in the } 2015 \text { Fall student } \\
\text { survey data. }\end{array}$ & $\begin{array}{l}\text { Dependent samples t-test 6: } \\
\text { (Shapiro-Wilk test p-value is .192) } \\
\text { Comparing the pre and post Focused } \\
\text { Attention scores in the } 2016 \text { Spring student } \\
\text { survey data. }\end{array}$ \\
\hline
\end{tabular}

\section{Faculty Open-ended Survey Data Analysis}

The research team read the pre- and post-survey answers on a line-by-line basis, independently taking analytical memos of the themes and patterns, and upon finishing, joined together to compare and discuss their analytical memos, re-read the survey answers, and made revisions of the emerged themes and patterns. The revisions continued until no new themes and patterns were identified, agreement was reached, and the themes and patterns became saturated (Strauss \& Corbin, 1998). 


\section{Classroom Observation Data Analysis}

The researchers conducted a content analysis (Hodder, 1994; Krippendorff, 2004) of the classroom observation data and predicted that the content analysis, as a research method of systematically and objectively describing and quantifying phenomena (Downe-Wamboldt, 1992; Krippendorff, 2004; Sandelowski, 1995), would shed light on teaching and learning in the ALC classes. More importantly, the content analysis was a research method that would help fulfill the purpose of providing knowledge, new insights, a representation of facts, and a practical guide to action (Krippendorff, 2004). Content analysis may be used in an inductive or deductive way depending on the purpose of the study (Elo \& Kyngas, 2008). Three typical approaches to conduct content analysis are: conventional, directed, or summative. The summative approach involves counting and comparisons by keywords or content (Hsieh \& Shannon, 2005). The content analysis in this study was inductive and adopted the summative approach. In the inductive content analysis process, the observation documents were read and analyzed with special attention to reveal how the classes observed were different and similar from each other in terms of the seven observation components specified on the observation protocol.

\section{Results}

\section{Quantitative data analysis results}

Two dependent samples t-tests were conducted to compare pre and post ELI scores for both 2015 Fall and 2016 Spring student survey data. The test result for 2015 Fall data, $t(68)=2.965$ and $p$ $=.004$, indicated that the post ELI score $(\mathrm{M}=3.732, \mathrm{SD}=.541)$ was significantly higher than the pre ELI score $(\mathrm{M}=3.499, \mathrm{SD}=.405)$. For 2016 Spring data, the test result was $\mathrm{t}(60)=.047$ and $\mathrm{p}=.962$ indicating that the post ELI score $(\mathrm{M}=.713, \mathrm{SD}=.770)$ was not significantly different from the pre ELI score $(\mathrm{M}=3.717, \mathrm{SD}=.485)$.

After the above t-tests on the overall ELI scores, data was broken down based on the three components (i.e., Meaningful Processing, Participation, and Focused Attention) to compare the pre- and post-test scores for each component. For the 2015 Fall survey, a dependent samples t-test comparing the pre and post Meaningful Processing score was conducted, as well as two Wilcoxon signed rank tests to respectively compare the pre and post Participation scores and the pre and post Focused Attention scores. The dependent samples t-test result, $\mathrm{t}(68)=.336$ and $\mathrm{p}=.738$, indicated that the pre $(\mathrm{M}=3.95, \mathrm{SD}=.394)$ and post $(\mathrm{M}=3.919, \mathrm{SD}=.759)$ Meaningful Processing scores are not significantly different. The result of the Wilcoxon signed Rank test for the Participation scores, $\mathrm{z}=3.921$ and $\mathrm{p}<.001$, indicated that the post Participation score $(\mathrm{M}=3.792, \mathrm{SD}=.549)$ were significantly higher than the pre score $(\mathrm{M}=$ $3.425, \mathrm{SD}=.582$ ). For the Focused Attention score, the Wilcoxon signed Rank test result is $\mathrm{z}=$ 4.344 and $\mathrm{p}<.001$ indicating that the post score $(\mathrm{M}=3.179, \mathrm{SD}=1.109)$ were significantly higher than the pre score $(\mathrm{M}=2.382, \mathrm{SD}=.731)$.

The researchers conducted three dependent samples t-tests to compare the pre- and postscores for the three components of Meaningful Processing, Participation, and Focused Attention in the 2016 Spring student survey data. The independent samples t-test result for the Meaningful Processing score is $\mathrm{t}(60)=1.629$ and $\mathrm{p}=.108$ indicating the pre score $(\mathrm{M}=3.934$ and SD $=.522)$ and the post score $(\mathrm{M}=3.772$ and $\mathrm{SD}=.851)$ are not significantly different. The dependent samples t-test result of $\mathrm{t}(60)=1.224$ and $\mathrm{p}=.226$ for the Focused Attention score 
tells the same story: there is no significance difference between the pre score $(\mathrm{M}=3.317$, SD $=.883)$ and the post score $(\mathrm{M}=3.476, \mathrm{SD}=1.073)$. As indicated by the dependent samples t-test result for the Participation score, $\mathrm{t}(60)=2.36$ and $\mathrm{p}=.022$, the post score $(\mathrm{M}=3.798$, SD $=.797)$ is significantly higher than the pre score $(\mathrm{M}=3.541, \mathrm{SD}=.701)$.

\section{Classroom Observation Data Analysis Results}

The 2015 Fall classroom observation data included observations of five classes taught in the ALC. Of the five classes, three had corresponding classes taught in traditional classrooms by the same instructors. The 2016 Spring data included observations of eight classes taught in the ALC and four out the eight classes had corresponding classes taught in traditional classrooms by the same instructors. In total, combining classes observed in ALC and traditional classrooms, eight observations were conducted in 2015 Fall and twelve observations in 2016 Spring. In Table 4, the reported percentages of classes (either observed in the ALC or in traditional classrooms) with the presence of the seven active learning components is noted.

\section{Table 4. Percentages of classes demonstrating the seven active learning components}

\begin{tabular}{lccc} 
Criteria & Active Learning Classroom & Traditional Classroom \\
Active Learning Component 1 & $92 . \%$ & $71.4 \%$ \\
Active Learning Component 2 & $92.3 \%$ & $71.4 \%$ \\
Active Learning Component 3 & $100 \%$ & $71.4 \%$ \\
Active Learning Component 4 & $92.3 \%$ & $100 \%$ \\
Active Learning Component 5 & $76.9 \%$ & $28.6 \%$ \\
Active Learning Component 6 & $92.3 \%$ & $57.1 \%$ \\
Active Learning Component 7 & $92.3 \%$ & $57.1 \%$ \\
\hline
\end{tabular}

The percentages in Table 4 depict a general picture: 1) overall the ALC classes were more active than those classes taking place in traditional classrooms in terms of the seven active learning components; 2) the biggest differences between ALC and traditional classes lie in active learning components 5, 6, and 7, (i.e., the instructor gives students opportunity to perform exploration; the instructor creates an atmosphere conducive to doing learning activities; and there is collaborative learning [group learning] and each student actively contributes to the group); and 3) of the seven active learning components, ALC classes are weakest in the component 5. Further content analysis of the observation data identified three themes telling the qualitative stories behind the above general picture.

Theme 1: Diverseness and innovativeness in attracting and motivating students. The observation data showed that the Faculty Fellows did well in the "E" of Engage in the 5E Instructional Model. They used a myriad of activities to engage and attract students at the beginning of the classes. These activities not only included those more traditional ones, such as bingo games and YouTube video watching, but also those integrated with technology, such as an ice-breaker activity using Kahoot as a pre-quiz in which students use their smart devices to respond or a polling activity through pollwhere.com asking students to text in answers using their phones.

Theme 2: ALC learning space facilitating learning activities and conducive to active learning. What the observers frequently mentioned in their observation notes was the ease of 
moving the ALC furniture around to form different seating types to meet the needs of different learning activities. With the flexible and moveable furnishings in the ALC, the classes could easily proceed into group activities and back to class presentation or discussion. In one of the classes observed, the students worked in groups. Each of the groups introduced a movie scene and then acted them out. The students moved the furniture around to serve the needs of their performance. This was not possible in traditional classrooms with stationary furniture.

Theme 3: Affordability of ALC learning space limited by the number of student enrollment. The researchers used the word "affordability" to refer to the capability of the ALC flexible furnishings to support learning needs. As shown by the observation data, the affordability of the ALC was limited by the number of students enrolled in a class. In classes with more than 25 students enrolled, the Steelcase ${ }^{\circledR}$ flexible furnishings became limited in accommodating the needs of class learning activities.

Theme 4: Inadequate opportunity for applying new concepts or knowledge. One of the $5 E s$ is the "E" of Elaboration referring to giving students opportunities to apply newly acquired knowledge or concepts. The observation data indicated that the Faculty Fellows did not do a good job in Elaboration. The content analysis of the learning activities noted by the observers showed that the ALC students were given very little opportunity to apply newly acquired concepts or knowledge.

\section{Faculty survey data analysis results}

The researchers analyzed the pre- and post- faculty open-ended survey data collected in 2015 Fall and 2016 Spring. As a result, three themes emerged. Quotation marks in the following section are used to indicate direct quotations from the faculty members' answers to the openended survey questions.

Theme 1: ALC engages students and facilitates learning in multiple ways. Based on the Faculty Fellows' responses, the ALC has the following characteristics:

- a flexible environment where students have more options of where to sit in the classroom;

- moveable furniture allowing for easier and simpler transition between activities and rearrangement of the room;

- different function areas where students can study "at the bar," "in the living room," or "work in smaller groups"; and

- useful resources such as the multi-functional dry erase boards, the interactive white board, and the charging stations.

Students demonstrated excitement about the new environment, and more importantly, the ALC created a relaxed atmosphere that "lowered the students" affective threshold" and made the student feel comfortable. As put by some Faculty Fellows, "a comfortable student is more likely to engage" and "comfort is a great contributor to motivation." While the unique flexible furnishings in the ALC "encouraged more peer interaction and collaborative work," the resources in the ALC gave more opportunities for hands-on activities and free explorations. One Faculty Fellow mentioned that "peer interaction gave the students incentive to have their prep done for class - no one wanted to be the unprepared one in their group." For some Faculty Fellows, the ALC facilitated learning by keeping their students more alert and focused because "this furniture forces them to be active and present" and "they cannot 'hide' anywhere in this room because of the capability to move and view each person in the classroom." Some Faculty 
Fellows even reported better learning outcomes and faster processing of concepts and techniques among their students.

Theme 2: ALC teaching experience promotes student-centered teaching practices. For most of the Faculty Fellows, lesson planning had always been writing a list of things to be covered in the class and lecture a huge part of how they taught their students. But after being recruited as ALC Faculty Fellows, they adopted the 5E Instructional Model for lesson planning, with some of them feeling forced or obliged to use the model and some feeling motivated to use it after the ALC workshop. Despite the differences in how they felt about getting started using the 5E Instructional Model, one change was common for the Faculty Fellows: they became more aware of students' learning needs and how to affect active and positive learning experiences among their students. A good example is a Faculty Fellow who had classes with typically more than 50 students. The 5E Instructional Model made him feel the need to engage his students and help them feel personally connected to their learning. He, therefore, started "dividing the class in half and placing the students in small work groups to allow them to share". He noticed that even such a small change in his instructional practices produced positive effects of "more questions and interactions were seen from the students."

The survey data revealed the Faculty Fellows' change in teaching practices towards more student-centered pedagogy. One Faculty Fellow commented in his survey that "The 5E Instructional Model did not miraculously make the class totally student-centered, but it forced me to think of ways to make it more so." What was said by a Faculty Fellow well summarized the change in pedagogy as a result of the ALC teaching experience, "It was, 'I do it; We do it; Y'all do it' - gradual release of the responsibility for learning to students." The following quote from this faculty fellow's post survey illustrates a change in pedagogy:

I have used the $5 \mathrm{E}$ model in my composition classes, and it works very well in the active learning center, again, because of the movable furniture and potential class arrangement. The class would work in groups to engage in the topic (pre-reading assignment). For example, before reading an essay about body image and female identity, the groups explored the topic of American standards of beauty as seen in the media. They recorded their findings on the white boards, which were then shared with the class. After reading the essay, the students took a reading quiz individually and then returned to their groups to answer analytical questions about the essay (more exploration), which were also shared with the class. During both sharing sessions, I would interrupt to explain or elaborate as necessary. The essays each student wrote served as the evaluation for each project.

Theme 3: Explore and Elaborate are two weak spots. The Explore and Elaborate were the most difficult of the 5Es to implement. The Faculty Fellows believed that they did very well in the Engage stage, and the survey data supported this belief showing that the Faculty Fellows were very creative in engaging their students from the beginning. However, when it comes to Explore and Elaborate, they found that "the Explore part was the worst" for them or "it was hard to get deep into the Explore phase," to use the Faculty Fellows' own words. According to some Faculty Fellows, the bulk of their classes was used to be Explain, and it would take time for them to become more capable of creating opportunities for students to explore and apply new concepts or knowledge. Some Faculty Fellows pointed out that the traditional idea that "the Elaborate would be done mostly out of class through home assignments" may explain why the Faculty Fellows were not observed often in the Elaborate stage. 


\section{Discussion}

The results from the student survey data analysis indicated that the ALC learning experience improves student engagement in terms of Participation for both 2015 Fall and 2016 Spring) and Focused Attention for 2015 Fall but never in terms of Meaningful Processing. Why is this the case? The results from the classroom observation and faculty survey data analysis helped shed light on this. Of the 5Es in the 5E Instructional Model, the faculty did a great job in Engage. Adding to this is the unique characteristics of the ALC that excited the students, made them feel relaxed and comfortable, kept them alert and attentive, and created a participatory classroom environment. With the aforementioned findings from the qualitative data analysis, it is not surprising to have the quantitative finding that the ALC learning experience improved students' participation and attentiveness as measured by the two components of Participation and Focused Attention in the student surveys.

The Meaningful Processing component in the student survey represents students' cognitive processing of new information and efforts to relate new material to pre-existing knowledge or determine its personal relevance. From a constructivist point of view, learning is a dynamic internal process where learners actively "construct" knowledge by connecting new information to what they already know (Falk, 2009), and knowledge is constructed in the mind of the learner as a consequence of working through real-world situations (Falance, 2001). To be more specific, "to understand is to discover, or reconstruct by rediscovery," (Piaget, 1973) and learning is a nonlinear process requiring extended periods of time to visit and revisit ideas until they are organized into coherent, stable, and general understanding (Bruner, 1966). The constructivist paradigm of learning documented in the literature highlights the importance of giving students sufficient opportunity to explore and to apply in order to make meaningful processing happen. Unfortunately, the findings from the classroom observation data and the faculty survey data showed that the Explore and the Elaborate were not well done. This may partially explain the insignificant results from comparing the post- and pre- Meaningful Processing scores.

The qualitative findings of this study indicate that the ALC is a learning space that promotes student-centered teaching practices and facilitates active learning by which students increase their knowledge through meaningful interactions with peers and faculty within their educational environment (Folkins, Friberg, Cesarini, 2015; Park \& Choi, 2014). The qualitative findings contribute to the literature by revealing the mechanism of how an active learning space works to engage students, improve the learning experience, and facilitate instruction. At the same time, the qualitative findings provide empirical evidence showing the extent to which an active learning space can promote learning is limited by the number of students enrolled and is partially decided by how teaching is planned and implemented.

\section{Conclusion, Implications for Practice, and Directions for Future Research}

This study yielded qualitative findings indicating:

1. The ALC engages students and improves the learning experience by creating a relaxing and comfortable environment, by promoting peer interactions, and through its flexible and versatile furnishings.

2. There is a paradigm shift towards student-centered teaching practices. 
3. The number of students enrolled in a class affects the capability of an active learning space to promote learning.

4. Of the 5Es in the 5E Instructional Model, the Explore and Elaborate are harder to find their presence in teaching practices.

Quantitatively, this study shows that the ALC experience significantly improves students' learning engagement in terms of Participation, but it has no effects on students' learning engagement as measured by Meaningful Processing, which may be related to insufficient opportunity to explore and apply in class. Since the quantitative result for Focused Attention was significant for 2015 Fall but insignificant for 2016 Spring, future research is needed to verify the effects of ALC experience on students' engagement in terms of Focused Attention.

The findings of this study carry the following implications for instructors and professional development providers: a) A learning space similar to the one in the ALC can be used to engage students and promote active learning, b) Be aware of the capacity of an active learning space in terms of the number of students it can accommodate, and c) Effective professional development programs need to be developed to help faculty improve their teaching practices regarding the Explore and Elaborate.

Embracing the 5E Instructional Model as its conceptual framework, this study limited its conclusion of instructors' instructional practices within the $5 \mathrm{E}$ dimensions. It is beyond the scope of this study to generalize instructors' instructional practice changes outside the 5E's. It is also beyond the scope of this study to produce empirical evidence that instructors' performance in the two Es of Explore and Elaborate is related to student engagement in terms of Meaningful Processing. The researchers envision that future research will be conducted not only to confirm but to quantify this relationship. In addition, this study has given rise to some questions worth future attention: What are students' perceptions of active learning? How can professional development help faculty to be more skillful and knowledgeable in the Explore and Elaborate of the 5E Instructional Model? How is the ALC experience related to student learning outcomes? What improvement is needed to make the learning space in the ALC more engaging and supportive? These questions serve as new directions for future research in active learning and learning space design.

\section{Acknowledgement}

This work was made possible by the award of an Active Learning Center Grant from Steelcase ${ }^{\circledR}$ Education. Any opinions, findings, and conclusions or recommendations expressed in this material are those of the authors and do not necessarily reflect the views of Steelcase ${ }^{\mathbb{B}}$ Education.

\section{Appendices}

\section{Appendix 1. Original ELI Survey Instrument.}

The original Engaged Learning Index developed and validated by Schreiner and Louis (2006).

1) I can usually find ways of applying what I'm learning in class to something else in my life.

2) I feel energized by the ideas that I am learning in most of my classes.

3) I feel as though I am learning things in my classes that are worthwhile to me as a person. 
4) I am learning a lot in most of my classes this semester.

5) I find myself thinking about what I'm learning in class even when I'm not in class.

6) I often discuss with my friends what I'm learning in class.

7) I usually think about how the topics being discussed in class might be connected to things I have learned in previous class periods.

8) When I am learning about a new idea in a class, I think about how I might apply it in practical ways.

9) Sometimes I get so interested in something I'm studying in class that I spend extra time trying to learn more about it.

10) I regularly participate in class discussions in most of my classes.

11) I ask my professors questions during class if I do not understand.

12) Sometimes I am afraid to participate in class.

13) Often I find my mind wandering during class.

14) In the last week, I've been bored in class a lot of the time.

15) It's hard to pay attention in many of my classes.

\section{Appendix 2. ELI Survey Instrument used in this Study.}

The Engaged Learning Index (ELI) in this study adapted from the original ELI developed and validated by Schreiner and Louis (2006).

1) I can find ways of applying what I have learned in my ALC class to something else in my life.

2) I feel energized by the ideas that I have learned a lot in my ALC class.

3) I feel as though I am learning things in my ALC class that are worthwhile to me as a person.

4) I find myself thinking about what I have learned in my ALC class even when I'm not in class.

5) I often discussed with my friends what I have learned in my ALC class.

6) I usually think about how the topics being discussed in my ALC class might be connected to things I have learned in previous class periods.

7) When I am learning about a new idea in my ALC class, I think about how I might apply it in practical ways.

8) Sometimes I got so interested in something from my ALC class that I spent extra time trying to learn more about it.

9) I regularly participated in class discussions in most of my ALC class.

10) I asked my professor questions during my ALC class if I did not understand.

11) Sometimes I was afraid to participate in my ALC class.

12) Often I found my mind wandering during my ALC class.

13) I got bored in my ALC class a lot of the time.

14) It was hard to pay attention in my ALC class.

\section{References}

Adedokun, O., Parker, L., Henke, J., \& Burgess, W. (2017). Student Perceptions of a 21st Century Learning Space. Journal of Learning Spaces, 6(1). Retrieved from http://libjournal.uncg.edu/jls/article/view/1339 
Baepler, P., \& Walker, J.D. (2014). Active learning classrooms and educational alliances: Changing relationships to improve learning. New Directions for Teaching and Learning, 2014 (137), 27-1640. doi: 10.1002/t1.20083

Basye, D., Grant, P., Hausman, S., \& Johnston, T. (2015). Get active: Reimagining learning spaces for student success. Eugene, OR and Arlington, VA: International Society for Technology in Education.

Beichner, R. J. (2014). History and evolution of active learning spaces. New Directions for Teaching and Learning, 2014 (137), 9-16. doi: 10.1002/t1.20081

Braxton, J. M., Milem, J. F., \& Sullivan, A. S. (2000). The influence of active learning on the college student departure process: Toward a revision of Tinto's theory. The Journal of Higher Education, 71(5), 569-590. doi. 10.2307/2649260

Brooks, D. C. (2011). Space matters: The impact of formal learning environments on student learning. British Journal of Educational Technology, 42(5). 719-726. doi:10.1111/j.14678535.2010.01098.x

Brooks, D. C. (2012). Space and consequences: The impact of different formal learning spaces on instructor and student behavior. Journal of Learning Spaces, 1(2). Retrieved from http://libjournal.uncg.edu/jls/article/view/285/282

Brooks, D. C., \& Solheim, C.A. (2014). Pedagogy matters, too: The impact of adapting teaching approaches to formal learning environments on student learning. New Directions for Teaching and Learning, 2014 (137), 53-61. doi: 10.1002/t1.20085

Brooks, D. C., Walker, J.D., \& Baepler, P. (2014). Editors' notes. New Directions for Teaching and Learning, 2014 (137), 1-7. doi: 10.1002/t1.20080

Bruner, J. (1966). The process of education. Cambridge, Mass.: Harvard University Press.

Bybee, R. W. (2014). The BSCS 5E instructional model: Personal reflections and contemporary implications. Science and Children, 5l(8), 10-13. doi:10.2505/4/sc14_051_08_10

Chickering, A. W., \& Gamson, Z. F. (1987). Seven principles for good practice in undergraduate education. AAHE Bulletin, 39(7), 2-7. doi:10.1016/0307-4412(89)90094-0

Creswell, J. W. (2009). Research design: Qualitative, quantitative, and mixed methods approaches (3rd ed.). Los Angeles, CA: SAGE Publications Inc.

Daly, C. J. (2011). Faculty learning communities: Addressing the professional development needs of faculty and the learning needs of students. Currents in Teaching and Learning, 4(1), 3-16.

Downe-Wamboldt, B. (1992). Content analysis: method, applications and issues. Health Care for Women International, 13, 313-321.

Elo, S., \& Kyngas, H. (2008). The qualitative content analysis process. Journal of Advanced Nursing, 62(1), 107-115.

Falance, T. (2001). Constructivism. In K. L. Medsker \& K. M. Holdsworth (Eds.), Models and strategies for training design (pp. 213-233). Silver Spring, MD: International Society for Performance.

Falk, B. (2009). Teaching the way children learn. New York, NY: Teachers College, Columbia University.

Folkins, J. W., Friberg, J. C., \& Cesarini, P. A. (2015). University classroom design principles to facilitate learning: The instructor as advocate. Planning for Higher Education Journal, $3(2), 45-62$.

Harris, M., \& Cullen, R. (2008). Learner-centered leadership: An agenda for action. Innovative Higher Education, 33, 21-28. doi: 10.1007/s10755-007-9059-3 
Hodder, I. (1994) The Interpretation of Documents and Material Culture. In: N. K. Denzin and Y. S. Lincoln (eds.), Handbook of Qualitative Research (pp. 393-402). London: Sage.

Hsieh, H. F., \& Shannon, S. E. (2005). Three approaches to qualitative content analysis. Qualitative Health Research, 15(9), 77-88. 10.1177/1049732305276687

Jessop, T., Gubby, L., \& Smith, A. (2012). Space frontiers for new pedagogies: A tale of constraints and possibilities. Studies in Higher Education, 37(2), 189-202. doi:10.1080/03075079.2010.503270

Keengwe, J. (2015). Handbook of research on educational technology and active learning. Hershey PA: IGI Global.

Kolis, M., Krusack, E., Stombaugh, A., Stow, R., \& Brenner, G.H. (2011). Designing learning lessons for the university classroom. Currents in Teaching and Learning, 4(1), 34-42.

Krippendorff, K. (2004). Content Analysis: An introduction to its methodology (2nd ed.). Thousand Oaks, CA: Sage.

Lumpkin, A., Achen, R. M., \& Dodd, R. K., (2015). Student perceptions of active learning. College Student Journal, 49(1), 121-133.

McArthur, J. (2015). Matching Instructors and Spaces of Learning: The impact of classroom space on behavioral, affective and cognitive learning. Journal of Learning Spaces, 4(1). Retrieved from http://libjournal.uncg.edu/jls/article/view/766

Michael, J. (2007). Faculty perceptions about barriers to active learning. College Teaching, 55 (2), 42-47. doi:10.3200/ctch.55.2.42-47

Miller, C. J., \& Metz, M. J. (2014). A comparison of professional-level faculty and student perceptions of active learning: Its current use, effectiveness, and barriers. Advanced Physical Education, 38, 246-252. doi:10.1152/advan.00014.2014

Montgomery, T. (2008). Space matters: Experiences of managing static formal learning spaces. Active Learning in Higher Education, 9(2), 122-38. doi: 10.1177/1469787408090839

National Aeronautics and Space Administration (n.d). 5Es overview: The 5E instructional model. Retrieved from http:/www.nasa.gov/audience/foreducators/nasaeclips/5eteachingmodels/

O'Leary, M. (2014). Classroom observations: A guide to the effective observation of teaching and learning. London: Routledge.

Park, E. L., \& Choi, B. K. (2014). Transformation of classroom spaces: Traditional versus active learning classroom in college. Higher Education, 68, 749-771. doi: 10.1007/s10734-0149742-0

Parsons, C. (2016). Space and consequences: The influence of the roundtable classroom design on student dialogue. Journal of Learning Spaces, 5(2). Retrieved from http://libjournal.uncg.edu/jls/article/view/1241

Pavlechko, G. M., \& Jacobi, K. L. (2014). Faculty development: Precursor to effective student engagement in the higher education learning space. In L. Scott-Webber, J. Branch, P. Bartholomew, \& C. Nygaard (Eds), Learning space design in higher education (pp. 169190). Faringdon, Oxfordshire; Libri Publishing.

Peterson, C. I., \& Gorman, K. S. (2014). Strategies to address common challenges when teaching in an active learning classroom. New Directions for Teaching and Learning, 2014 (137), 63-70. doi: 10.1002/t1.20086

Piaget, J. (1973). To understand is to invent. New York: Grossman.

Rands, M., \& Gansemer-Topf, A. (2017). "The room itself is active:" How classroom design impacts student engagement. Journal of Learning Spaces, 6(1). Retrieved from http://libjournal.uncg.edu/jls/article/view/1286 
Sandelowski, M. (1995) Qualitative analysis: what it is and how to begin? Research in Nursing \& Health, 18, 371-375.

Sawers, K., Wicks, D., Mvududu, N., Seeley, L., \& Copeland, R. (2016). What Drives Student Engagement: Is it Learning Space, Instructor Behavior or Teaching Philosophy?. Journal of Learning Spaces, 5(2). Retrieved from http://libjournal.uncg.edu/jls/article/view/1247

Schreiner, L., \& Louis, M. (2006, November). Measuring engaged learning in college students: Beyond the borders of NSSE. Paper presented at the annual meeting of the Association for the Study of Higher Education, Anaheim, CA.

Sickel, A. J., Witzig, S. B., Vanmali, B. H., \& Abell, S. K. (2013). The nature of discourse throughout 5E lessons in a large enrollment college biology course. Research in Science Education, 43(2), 637-665. doi:10.1007/s11165-012-9281-6

Steelcase. (2016). Our innovation legacy began when we received our first patent in 1914. Retrieved from https:/www.steelcase.com/corporate-information/

Strauss, A., \& Corbin, J. (1998). Basics of qualitative research (2nd ed.). Thousand Oaks: Sage Publications.

Sullivan, M. (2015). Maker, tinker, hacker? Active learning spaces in K/12 libraries. Library Media Connection, 33(5).

Umbach, P. D., \& Wawrzynski, M. R. (2005). Faculty do matter: The role of college faculty in student learning and engagement. Research in Higher Education, 46(2), 153-184. doi: 10.1007/s11162-004-1598-1

Tanner, K. D. (2010). Order matters: Using the 5E Instructional Model to align teaching with how people learn. CBE-Life Sciences Education, 9, 159-164. doi:10.1187/cbe.10-060082

Williams, N. (2010). Embracing student potential: Creating space for intrinsic motivation in community college developmental reading classes. Language Arts Journal of Michigan, 25(2), 35-43. doi:10.9707/2168-149X.1075

Journal of the Scholarship of Teaching and Learning, Vol. 18, No. 4, December 2018.

josotl.indiana.edu 